\title{
Identification of Makorin I as a novel SEREX antigen of esophageal squamous cell carcinoma
}

Hideaki Shimada1, Tooru Shiratori², Mari Yasuraoka ${ }^{3}$, Akiko Kagaya ${ }^{2,3}$, Mari Kuboshima ${ }^{2,3}$, Fumio Nomura ${ }^{4}$, Masaki Takiguchi ${ }^{3}$, Takenori Ochiai ${ }^{2,5}$, Hisahiro Matsubara ${ }^{2}$ and Takaki Hiwasa*3

\begin{abstract}
Address: ${ }^{1}$ Department of Gastroenterological Surgery, Chiba Cancer Center, Chiba, Japan, ${ }^{2}$ Department of Frontier Surgery, Chiba University, Graduate School of Medicine, Chiba, Japan, ${ }^{3}$ Department of Biochemistry and Genetics, Chiba University, Graduate School of Medicine, Chiba, Japan, ${ }^{4}$ Department of Molecular Diagnosis, Chiba University, Graduate School of Medicine, Chiba, Japan and ${ }^{5}$ Gastroenterological Center, SanAi Memorial Hospital, Chiba, Japan

Email: Hideaki Shimada - hshimada@chiba-cc.jp; Tooru Shiratori - swan@faculty.chiba-u.jp; Mari Yasuraoka - y9m1085@students.chibau.ac.jp; Akiko Kagaya - akikokagaya@graduate.chiba-u.jp; Mari Kuboshima - kuboji@graduate.chiba-u.jp;

Fumio Nomura -fnomura@faculty.chiba-u.jp; Masaki Takiguchi - mtak@faculty.chiba-u.jp; Takenori Ochiai - otiai@faculty.chiba-u.jp; Hisahiro Matsubara - matsuhm@faculty.chiba-u.jp; Takaki Hiwasa* - hiwasa_takaki@faculty.chiba-u.jp

* Corresponding author
\end{abstract}

Published: 15 July 2009

BMC Cancer 2009, 9:232 doi:10.1 |86/| 47|-2407-9-232
Received: 19 November 2008

Accepted: 15 July 2009

This article is available from: http://www.biomedcentral.com/I47I-2407/9/232

(c) 2009 Shimada et al; licensee BioMed Central Ltd.

This is an Open Access article distributed under the terms of the Creative Commons Attribution License (http://creativecommons.org/licenses/by/2.0), which permits unrestricted use, distribution, and reproduction in any medium, provided the original work is properly cited.

\begin{abstract}
Background: Esophageal squamous cell carcinoma (SCC) represents one of the most malignant tumors. To improve the poor prognosis, it is necessary to diagnose esophageal SCC at early stages using new tumor markers. SEREX (serological identification of antigens by recombinant cDNA expression cloning) is suitable for large-scale screening of tumor antigens and has been applied for various types of human tumors.

Methods: Tumor markers of esophageal squamous cell carcinoma (SCC) were screened by SEREX method. The presence of serum anti-makorin I (MKRNI) antibodies (s-MKRNI-Abs) was examined by Western blotting using bacterially expressed MKRNI protein. The expression levels of MKRNI mRNA in tissues were examined by RTPCR. The biological activity of MKRNI was examined by transfection of ras-NIH3T3 mouse fibroblasts with MKRNI cDNA. Major ubiquitinated proteins in MKRNI-transfected cells were identified by immunoprecipitation with anti-ubiquitin antibody followed by mass spectrometry.

Results: MKRNI was identified as a novel SEREX antigen of esophageal SCC. Although a total of $18(25 \%)$ of 73 patients with esophageal SCC had s-MKRNI-Abs, none of the 43 healthy donors had a detectable level of sMKRNI-Abs. There was no correlation between the presence of s-MKRNI-Abs and clinicopathological variables other than histological grading. Well-differentiated tumors were associated significantly with the presence of sMKRNI-Abs in the patients. The mRNA levels of MKRNI were frequently higher in esophageal SCC tissues than in the peripheral normal esophageal mucosa. Stable transfection of ras-NIH3T3 cells with MKRNI cDNA induced prominent morphological changes such as enlargement of the cell body and spreading. Ubiquitination of 80 - and 82-kDa proteins were clearly observed in MKRNI-transfected cells but not in the parental cells, which were identified as L-FILIP (filamin A interacting protein I).
\end{abstract}

Conclusion: MKRNI is a novel SEREX antigen of esophageal SCC, and s-NKRNI-Abs can be a candidate of diagnostic markers of esophageal SCC with high specificity. It is plausible that MKRNI is involved in carcinogenesis of the well-differentiated type of tumors possibly via ubiquitination of L-FILIP. 


\section{Background}

Esophageal squamous cell carcinoma (SCC) represents one of the most malignant tumors [1,2]. The poor prognosis of this tumor is attributed largely to a delay in diagnosis. Several tumor markers have been used for the diagnosis of esophageal SCC [3-5]. However, to improve the detection of esophageal SCC, new tumor markers are necessary. It has been known for several decades that the immune system is able to recognize tumor cells $[6,7]$. This was developed by Sahin et al. to establish a new method called SEREX (serological identification of antigens by recombinant cDNA expression cloning), which involves the immunoscreening of cDNA libraries prepared from tumor specimens with autologous or allogeneic sera [8]. Since clones isolated by SEREX can be easily identified by nucleotide sequencing, SEREX is suitable for large-scale screening of tumor antigens. SEREX screening of several different human tumor types has identified many novel tumor antigens $[9,10]$.

A previous application of the SEREX method to esophageal cancer resulted in the identification of NY-ESO-1, a cancer-testis antigen expressed in various cancer cells but not in normal tissues [8]. SEREX analysis has also led to the isolation of several antigens with known cancer relatedness, including a mutated version of the $\mathrm{p} 53$ tumor suppressor protein, while the presence of antibodies to p53 in serum was associated with poor prognosis in esophageal cancer [11-13]. We applied the SEREX methodology to esophageal SCC with the aim of adding to the catalogue of defined immunogenic proteins in human cancer [1421]. In this study, we report that makorin 1 (MKRN1) is a new tumor antigen of esophageal SCC.

\section{Methods}

\section{Human esophageal carcinoma cDNA library}

This study was approved by the Ethic Committee of Chiba University, Graduate School of Medicine. Collection of tissues and sera was agreed upon by patients and healthy donors, after provision of written, informed consent. Recombinant DNA work was done with official permission and in accordance with the rules of the government of Japan. The human esophageal SCC cell line, T.Tn, was established in the Department of Clinical Molecular Biology, Chiba University, Graduate School of Medicine $[22,23]$. Total RNA was prepared from T.Tn cells by the acid guanidinium thiocyanate-phenol-chloroform method [24] and purified to poly(A)+RNA using Oligotex$\mathrm{dT}_{30}$ (Super) mRNA Purification Kit (Takara Biochemicals, Kyoto, Japan) according to the manufacturer's instructions. cDNA was ligated into EcoRI-XhoI site of the $\lambda$ ZAP II phage. The original library size was $1.8 \times 10^{6}$.

\section{Sera of patients and healthy donors}

Sera were obtained from 73 esophageal cancer patients with various stages of disease progression, as well as from
16 breast, 16 gastric, and 16 colorectal cancer patients prior to treatment. The patients with esophageal carcinoma consisted of 66 men (82\%) and 7 women (18\%), with a median age of 65 years (range 39 to 86 years). No treatment-related death was observed in these patients. They were pathologically classified according to the TNM/ UICC classification [25] using resected specimens. The patients included 14 with stage I cancer, 21 with stage II, 27 with stage III, and 11 with stage IV cancer (Table 1 ). All patients underwent R0 resection with extended lymphadenectomy. After surgery, they were followed until the end of March 2006 or their deaths with clinical examinations and imaging studies on a regular basis. The median follow-up for survivors was 30 months. Each sample was centrifuged at 3,000 $\mathrm{g}$ for $5 \mathrm{~min}$ and then frozen at $-80^{\circ} \mathrm{C}$ until use. Repeated thawing and freezing of samples was avoided.

\section{CEA, CYFRA2I-I and SCC-Ag assays}

Serum CEA and CYFRA21-1 concentrations were measured with Enzymun-TEST CEA and Enzymun-TEST CYFRA21-1 (Boehringer Mannheim, Mannheim, Germany), respectively. SCC-Ag levels were measured in serum with an immunoradiometric Assay kit (Dynabott, Tokyo, Japan). The cutoff values for serum CEA, CYFRA21-1, and SCC-Ag levels were $4.6 \mathrm{ng} / \mathrm{ml}, 2.57 \mathrm{ng} /$ $\mathrm{ml}$ and $1.5 \mathrm{ng} / \mathrm{ml}$, respectively, in accordance with the manufacturer's instructions. The specificity at these cut-off values is $95 \%$.

\section{Immunological screening of the esophageal carcinoma cell antigens by SEREX}

Esophageal carcinoma antigens were screened by SEREX as previously published by Sahin et al. [8]. Escherichia coli XL1-Blue MRF' was infected with $\lambda Z A P$ II phage which contained a cDNA library, and the expression of cDNA was induced by blotting on nitrocellulose membranes (NitroBind, Osmonics Inc., Minnetonka, MN), which had been pretreated with $10 \mathrm{mM}$ isopropyl $\beta$-D-thiogalactoside (IPTG, Wako, Kyoto, Japan) for $30 \mathrm{~min}$. The membranes were then washed three times with TBS-T [ $20 \mathrm{mM}$ Tris-HCl (pH 7.5), $0.15 \mathrm{M} \mathrm{NaCl}$ and $0.05 \%$ Tween-20], and blocking was performed by treatment with $1 \%$ protease-free bovine serum albumin (Wako) in TBS-T for $1 \mathrm{~h}$. The membranes were exposed in 1:2000-diluted serum for $1 \mathrm{~h}$. After washing with TBS-T three times, the membranes were treated with 1:5000-diluted alkaline phosphatase-conjugated Fc fragment-specific goat anti-human IgG and making it react for $1 \mathrm{~h}$. Positive reactions were detected by incubation in color development solution [100 mM Tris- $\mathrm{HCl}$ (pH 9.5), $100 \mathrm{mM} \mathrm{NaCl}$ and $5 \mathrm{mM}$ $\mathrm{MgCl}_{2}$ ] containing $0.3 \mathrm{mg} / \mathrm{ml}$ of nitroblue tetrazolium chloride (Wako) and $0.15 \mathrm{mg} / \mathrm{ml}$ of 5-bromo-4-chloro-3indolyl-phosphate (Wako). Positive clones were recloned twice to obtain monoclonality and retested for serum reactivity. 
Table I: Relationship between s-MKRN I-Abs and the clinicopathological variables in 73 patients with esophageal SCC

\begin{tabular}{|c|c|c|c|c|}
\hline \multirow[b]{3}{*}{ Characteristics } & & \multicolumn{2}{|c|}{ s-MKRNI-Abs } & \multirow[b]{3}{*}{$P$ value } \\
\hline & & $\begin{array}{l}\text { Positive } \\
\text { (18 patients) }\end{array}$ & $\begin{array}{l}\text { Negative } \\
\text { (55 patients) }\end{array}$ & \\
\hline & & $\mathrm{n}(\%)$ & & \\
\hline \multicolumn{5}{|l|}{ Age } \\
\hline Median & $65 \mathrm{yrs}$ & & & \\
\hline \multirow[t]{3}{*}{ Range } & $39-86$ yrs & & & \\
\hline & Under 59 yrs & $6(33)$ & $21(38)$ & \\
\hline & Over 60 yrs & $12(67)$ & $34(62)$ & 0.711 \\
\hline \multirow[t]{2}{*}{ Sex } & Male & $16(89)$ & $50(91)$ & \\
\hline & Female & $2(11)$ & $5(9)$ & 0.555 \\
\hline \multirow[t]{6}{*}{ Location } & $\mathrm{Ce}$ & $0(0)$ & $4(7)$ & \\
\hline & Ut & $4(22)$ & $7(13)$ & \\
\hline & Mt & $9(50)$ & $29(53)$ & \\
\hline & $\mathrm{Lt}$ & $4(22)$ & $9(16)$ & \\
\hline & $\mathrm{Ae}$ & I (6) & $4(7)$ & \\
\hline & Unknown & $0(0)$ & $2(4)$ & 0.682 \\
\hline \multicolumn{5}{|l|}{ Tumor size } \\
\hline Median & $58.6 \mathrm{~mm}$ & & & \\
\hline \multirow[t]{4}{*}{ Range } & $15-140 \mathrm{~mm}$ & & & \\
\hline & Under $29 \mathrm{~mm}$ & $2(1 \mathrm{I})$ & $8(15)$ & \\
\hline & Over $30 \mathrm{~mm}$ & $13(72)$ & $47(85)$ & \\
\hline & Unknown & $3(17)$ & $0(0)$ & 0.636 \\
\hline \multirow[t]{4}{*}{ Histopathological Grading } & GX & $8(44)$ & $20(37)$ & \\
\hline & GI & $6(33)$ & $5(9)$ & \\
\hline & G2 & $4(22)$ & $21(38)$ & \\
\hline & G3 & $0(0)$ & $9(16)$ & 0.008 \\
\hline \multirow[t]{5}{*}{ Primary Tumor } & Tis & $0(0)$ & I (2) & \\
\hline & TI & $3(17)$ & $16(29)$ & \\
\hline & $\mathrm{T} 2$ & $4(22)$ & $10(18)$ & \\
\hline & T3 & $5(28)$ & $13(24)$ & \\
\hline & $\mathrm{T} 4$ & $6(33)$ & $15(27)$ & 0.824 \\
\hline \multirow[t]{2}{*}{ Regional Lymph Nodes } & No & $3(17)$ & $17(31)$ & \\
\hline & $\mathrm{NI}$ & $15(83)$ & $38(69)$ & 0.194 \\
\hline \multirow[t]{2}{*}{ Distant Metastasis } & Mo & $16(89)$ & $46(84)$ & \\
\hline & MI & $2(11)$ & $9(16)$ & 0.455 \\
\hline \multirow[t]{6}{*}{ Stage Grouping } & Stage 0 & $0(0)$ & I (2) & \\
\hline & Stage I & $I(6)$ & $12(22)$ & \\
\hline & Stage IIA & $I(6)$ & $3(5)$ & \\
\hline & Stage IIB & $6(33)$ & II (20) & \\
\hline & Stage III & $8(44)$ & $19(35)$ & \\
\hline & Stage IV & $2(11)$ & $9(16)$ & 0.552 \\
\hline \multicolumn{5}{|l|}{ Tumor Markers } \\
\hline \multirow{3}{*}{ SCC-Ag } & Positive & 7 (39) & $19(35)$ & \\
\hline & Negative & $11(6 I)$ & $32(58)$ & \\
\hline & ND & $0(0)$ & $4(7)$ & 0.902 \\
\hline
\end{tabular}


Table I: Relationship between s-MKRNI-Abs and the clinicopathological variables in 73 patients with esophageal SCC (Continued)

\begin{tabular}{|c|c|c|c|c|}
\hline \multirow[t]{3}{*}{ CYFRA2I-I } & Positive & $3(17)$ & $13(24)$ & \\
\hline & Negative & $15(83)$ & $38(69)$ & \\
\hline & ND & $0(0)$ & $4(7)$ & 0.340 \\
\hline \multirow[t]{3}{*}{ CEA } & Positive & $2(11)$ & $12(22)$ & \\
\hline & Negative & 16 (89) & 37 (67) & \\
\hline & ND & $0(0)$ & $6(11)$ & 0.199 \\
\hline
\end{tabular}

\section{Sequence analysis of identified antigens}

Monoclonalized phage cDNA clones were converted to pBluescript phagemid by in vivo excision using the ExAssist helper phage (Stratagene, La Jolla, CA). Plasmid DNA was obtained from Escherichia coli SOLR strain transformed by the phagemid. The cDNA inserts were sequenced by the dideoxy chain termination method using the DNA Sequencing kit BigDyeTM Terminator (Applied Biosystems, Foster City, CA) and ABI PRISM 3700 DNA Analyzer (Applied Biosystems). Sequences were analyzed for homology with public databases of known genes and proteins using NCBI-BLAST.

\section{Western blotting analysis}

Escherichia coli JM109 cells which contained cDNA clones recombined in pBluescript II were cultured with or without $0.1 \mathrm{mM}$ IPTG for $2.5 \mathrm{~h}$. Cells were then washed with phsphate-buffered saline and lysed by incubation at $100^{\circ} \mathrm{C}$ for $3 \mathrm{~min}$ in SDS sample buffer [26]. Escherichia coli lysate was then subjected to SDS-PAGE followed by western blotting using sera of 73 patients with esophageal cancer, 14 with breast cancer, 9 with gastric cancer, and 16 with colorectal cancer.

\section{Statistical analyses}

The chi-square test or Fisher exact test (2-sided) was performed. The survival probabilities were calculated using the product-limit method of Kaplan and Meier, considering all deaths. Survival differences between groups were determined using the log-rank test. Fisher's exact probability test was used to determine the significance of the differences between two groups. All statistical analyses were carried out using the Stat View 5.0 program for Windows (SAS Institute Inc., Cary, NC). P values at the 0.05 level were considered statistically significant.

\section{Reverse transcription-PCR (RT-PCR)}

Total cellular RNA was isolated from the T.Tn esophageal SCC cell line using AquaPure RNA Isolation Kit (Bio-Rad, Hercules, CA), or from the tumor tissues using FastPure RNA Kit (Takara Bio, Otsu, Japan). RNA of normal esophageal keratinocytes was purchased from Cybrdi (Frederick, MD). Reverse transcription was performed with an oligo(dT $)_{20}$ primer using the ThermoScript RTPCR System (Invitrogen). The presence of MKRN1 tran- scripts was examined via PCR amplification using the following primers: sense, 5'-AACGGGTGCCTCAGTG TCCTT-3'; antisense, 5'-CTCCTGATGTTGTGGCTGTTG3'. $\beta$-actin-specific PCR primers (sense, 5'-ACCACAGCTGAGAGGGAAATC-3'; antisense, 5'-AGCACTGTGTTGGCATAGAGG-3') were used as a loading control. PCR was performed using KOD-Plus-DNA polymerase (Toyobo, Osaka, Japan) as follows: an initial denaturation step at $94^{\circ} \mathrm{C}$ for $3 \mathrm{~min}$, followed by 33 cycles for MKRN1 or 25 cycles for $\beta$-actin of denaturation at $94^{\circ} \mathrm{C}$ for $15 \mathrm{sec}$, annealing at $60^{\circ} \mathrm{C}$ for $30 \mathrm{sec}$, and extension at $68^{\circ} \mathrm{C}$ for $30 \mathrm{sec}$, with a final extension of $5 \mathrm{~min}$ at $68^{\circ} \mathrm{C}$.

\section{Isolation of stable transfectants}

Activated Ha-ras-transformed NIH3T3 mouse fibroblasts (clone F25) (ras-NIH3T3) [27,28] were cultured in Dulbecco's modified Eagle's medium (Nissui Pharmaceutical, Tokyo, Japan) supplemented with 5\% heat-inactivated bovine serum. Eukaryotic expression vector pME18S-FL3 containing human MKRN1 cDNA was purchased from Toyobo (Osaka, Japan). ras-NIH3T3 cells $\left(5 \times 10^{4}\right.$ cells) were co-transfected with MKRN1 cDNA and neo gene using Lipofectamine reagent (Invitrogen) as described $[28,29]$. After culture in the presence of G418 $(400 \mu \mathrm{g} / \mathrm{ml})$ for two weeks, surviving colonies were isolated.

\section{Peptide synthesis and generation of polyclonal antibodies} Two peptides consisting of amino acids between 104 and 118 (CRYEHSKPLKQEEAT) and of amino acids between 399 and 412 (EPQRQKVGTSSRYR) from the MKRN1 protein were synthesized and called MKRN1-K1 and K2, respectively. The peptide was coupled to keyhole limpet haemocyamine that had been activated with N-succinimidyl-3-maleinimido-proprionate. To obtain antibodies, rabbits (bastards) were immunized by subcutaneous injections of $300 \mu \mathrm{g}$ of coupled peptide emulsified in Freund's complete adjuvant. The immunization was repeated twice at 2-week intervals with the same amount of coupled peptide in Freund's incomplete adjuvant. The titer was tested after each bleed by enzyme-linked immunosorbent assay (ELISA).

Peptide-specific antibodies were enriched by using the pretested rabbit serum columns (Amersham Biosciences, Piscataway, NJ) according to the manufacturer's instruc- 
tions. In brief, $6 \mathrm{mg}$ of the MKRN1 peptide were coupled to the NHS-activated Sepharose column. Six ml of the rabbit serum were diluted 1:10 with $10 \mathrm{mM}$ Tris- $\mathrm{HCl}(\mathrm{pH}$ 7.5) and the diluted serum was applied twice to the equilibrated column. Antibodies were eluted with $100 \mathrm{mM}$ glycine buffer $(\mathrm{pH}$ 2.5). Fractions were immediately neutralized with $1 \mathrm{M}$ Tris- $\mathrm{HCl}(\mathrm{pH} 8.0)$. The final concentration of the purified serum was 1:1.83.

\section{Peptide mass fingerprinting}

Extracts of MKRN1-transfected ras-NIH3T3 cells were immunoprecipitated with anti-ubiquitin antibody (Santa Cruz) followed by SDS-polyacrylamide gel electrophoresis as described previously [30]. The gel was stained with silver (Invitrogen) and the gel pieces containing 80- and $82-\mathrm{kDa}$ proteins were washed with water and dehydrated with acetonitrile. After removing acetonitrile, the gel piece was dried in a vacuum centrifuge, supplied with $10 \mathrm{mM}$ dithiothreitol in $100 \mathrm{mM}$ ammonium bicarbonate, and incubated for $1 \mathrm{~h}$ at $56^{\circ} \mathrm{C}$. The solution was replaced by the same volume of $55 \mathrm{mM}$ iodoacetamide in $100 \mathrm{mM}$ ammonium bicarbonate and incubated for $45 \mathrm{~min}$ at room temperature in the dark. The gel piece was washed with $100 \mathrm{mM}$ ammonium bicarbonate, dehydrated with acetonitrile, rehydrated with $100 \mathrm{mM}$ ammonium bicarbonate, dehydrated again with acetonitrile, and dried in a vacuum centrifuge following elimination of acetonitrile. The dried gel piece was immersed in trypsin solution containing $10 \mu \mathrm{g} / \mathrm{ml}$ trypsin in $50 \mathrm{mM}$ ammonium bicarbonate and $5 \mathrm{mM}$ calcium chloride, incubated for $45 \mathrm{~min}$ at $4^{\circ} \mathrm{C}$, and further at $37^{\circ} \mathrm{C}$ for $12 \mathrm{~h}$. Peptides were extracted using sequential steps of $20 \mathrm{mM}$ ammonium bicarbonate, followed by $5 \%$ formic acid in $50 \%$ acetonitrile. The extract was dried in a vacuum centrifuge, supplied with $0.1 \%$ trifluoroacetic acid and desalted using ZipTip C18 (Millipore) according to the manufacturer's protocol. The peptides were eluted with $0.1 \%$ trifluoroacetic acid in $50 \%$ acetonitrile and applied onto MALDI plate.

\section{Mass spectrometry}

Mass spectrometry of peptides was performed using MALDI-TOF MS AXIMA-CFR (Shimadzu Corporation, Tsukuba, Japan). Protein identification was performed using Mascot search (Matrix Science, http://www.matrix science.com/).

\section{Results}

\section{Serological screening of T.Tn cell cDNA library}

A total of approximately $2 \times 10^{7}$ pfu from the T.Tn cDNA library were screened using serum samples derived from 21 patients with esophageal SCC. One of the isolated clones, 15J1-3, showed strong homology with the makorin1 (MKRN1; NCBI accession number: NM_013446) gene. MKRN1 appeared to be of much interest because its expression is much higher in the brain and testis than other tissues [31]. A recent report revealed that MKRN1 is involved in the differentiation of various tissues including osteoblasts, eye epithelial cells and kidney [32].

\section{Immune recognition of MKRNI gene product in patients with eophageal SCC}

The existence of antibodies against the MKRN1 gene product was examined with 73 sera of patients with esophageal SCC and 43 sera of healthy donors by Western blot analysis. In order to confirm that the antigen reacting with serum antibodies derives from the insert cDNA, protein extracts of IPTG-treated Escherichia coli bearing MKRN1 cDNA expression plasmids or the control empty plasmids were compared with those of non-treated bacteria. The 50-kDa band which appeared only in MKRN1-expressing bacteria in response to IPTG was judged as positive. Figure 1 shows the representative results of s-MKRN1-Abs-negative serum of a healthy donor, \#1, and s-MKRN1-Abs-positive serum of a patient, \#15. For this 50-kDa band, 18 of $73(25 \%)$ sera of patients with esophageal SCC were seropositive (data not shown). In contrast, all 43 healthy donors were sero-negative. Similarly, positive bands were detected in the sera of two of $14(14 \%)$ breast cancer patients, none of the $9(0 \%)$ gastric cancer patients and six of the $16(38 \%)$ colon cancer patients (data not shown).

\section{Presence of serum anti-MKRNI antibodies and clinicopathological variables of esophageal SCC}

We then examined the relationship between the presence of s-MKRN1-Abs and the clinicopathological features of the patients (Table 1). As for histopathological grading, well-differentiated tumors (G1) were associated with the presence of s-MKRN1-Abs significantly compared to poorly differentiated tumors (G3), and vice versa $(P=$ $0.008)$. Nodal involvement was more frequently observed in the patients with s-MKRN1-Abs than in those without s-MKRN1-Abs, yet the difference was not statistically significant $(P=0.194)$. There was no correlation between the presence of s-MKRN1-Abs and other features such as age, gender, location, tumor sizes, depth of tumor, distant metastasis and stages. Kaplan-Meier plotting showed no significant correlation between s- MKRN1-Abs and survival (Figure 2).

\section{Correlation between the presence of s-MKRNI-Abs and positivity of conventional serum tumor markers}

When the patients were divided into two groups according to the presence of s-MKRN1-Abs, there was no significant correlation between the presence of s-MKRN1-Abs and the positivity of conventional serum tumor markers (Table 1). Consequently, the sensitivity of serum markers to detect esophageal SCC was improved by using sMKRN1-Abs in combination with conventional markers. For example, the positivity increased from 36\% of SCC-Ag 
alone to $51 \%$ by combination of s-MKRN1-Abs and SCCAg.

Increased expression of MKRNI mRNA in esophageal SCC The expression levels of MKRN1 mRNA in esophageal tissue specimens of SCC or normal cells were examined by RT-PCR analysis. T.Tn esophageal SCC cells, as a positive control, showed higher MKRN1 mRNA levels than normal esophageal keratinocytes (Figure 3). MKRN1 mRNA levels in carcinoma tissues were higher than those in the normal counterparts of patient numbers 2, 6, 7, 8 and 10 . Thus, this elevated expression may account for the development of s-MKRN1-Abs.

\section{Ubiquitination of L-FILIP was stimulated by MKRN I}

To examine the biological role of MKRN1, human MKRN1 cDNA was recombined in pcDNA3-Myc, His and transfected into ras-NIH3T3 cells as described [28]. The protein (Figure 4a) and mRNA (Figure $4 \mathrm{~b}$ ) of transduced MKRN1 were observed in a stable transfected clone, Fmkrn-24, but not in the parental ras-NIH3T3 cells. The phase morphology of Fmkrn-24 was markedly different from the parental cells; i.e. enlargement of cell bodies with flat and extended cell periphery (Figure 4c). Because E3 ubiquitin-protein ligase activity was suspected to MKRN1 [31,33], ubiquitinated proteins were examined by Western blotting using anti-ubiquitin antibody. Two ubiquitinated proteins of 80 and $82 \mathrm{kDa}$ were clearly observed in two MKRN1 transfectants but not in the parental ras-NIH3T3 cells (Figure 4a). These two proteins in Fmkrn-24 cells were immunoprecipitated with antiubiquitin antibody, separated by SDS-polyacrylamide gel electrophoresis and analyzed by mass spectrometry. Six tryptic polypeptides were completely matched to the sequence of mouse L-FILIP (filamin A interacting protein 1) (Figure 5). This suggests that the ubiquitination of LFILIP was induced by MKRN1.

\section{Discussion}

In the current study, we applied SEREX analysis to esophageal SCC, and identified MKRN1. MKRN1 locus maps to a conserved syntenic group near the T-cell receptor cluster in chromosome 7q34 [31]. MKRN1 is widely expressed in mammals at high levels in the murine embryonic nervous system and adult testis. Thus far, several MKRN1-related genes have been reported, and MKRN1 is the ancestral founder of the MKRN1 gene family. This family encodes putative ribonucleoproteins with a distinct collection of four zinc-finger motifs followed by a RING zinc-finger [31]. E3 ubiquitin-protein ligase activity is intrinsic to RING domain-containing molecules such as $\mathrm{Mdm} 2$ and cCbl. Kim et al. have shown that MKRN1 binds and promotes ubiquitination of TERT and subsequent proteasomal degradation [33]. On the other hand, Hirotsune et al. have reported that a putative pseudogene-induced desta-

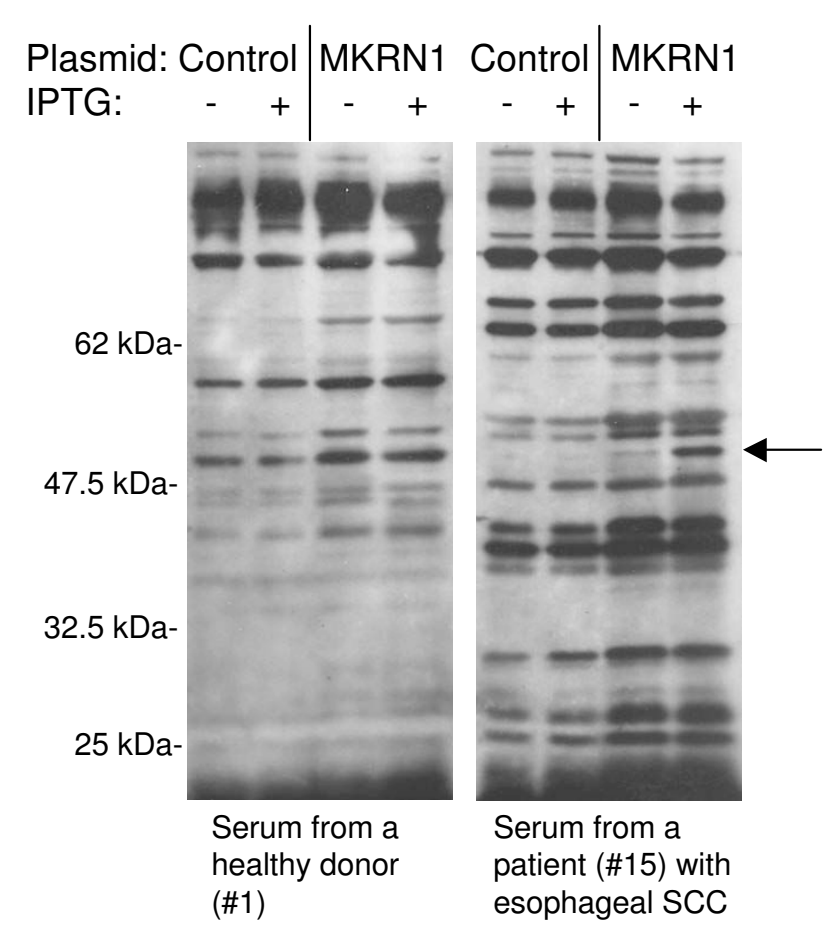

Figure I

Recognition of MKRN I by serum antibodies in patients with esophageal SCC. Escherichia coli containing MKRNI cDNA expression plasmid (MKRNI) or control empty plasmid (Control) was treated with (+) or without (-) IPTG for $2.5 \mathrm{~h}$, and cell lysates were subsequently subjected to Western blot analysis using the sera from healthy donor \#I and esophageal SCC patients \#I5 as indicated. An arrow indicates the IPTG-induced polypeptide that represents the encoded MKRNI cDNA product.

bilization of MKRN1 led to defects of differentiation such as polycystic kidneys and bone deformity [32].

The presence of serum MKRN1 antibodies (s-MKRN1Abs) in cancer patients was examined by Western blotting (Figure 1). s-MKRN1-Abs were frequently observed in patients with esophageal SCC $(25 \%)$ and colon carcinoma (38\%) but not in healthy donors. Even in patients with early-stage (T1) esophageal tumors, s-MKRN1-Abs were positive for $3(16 \%)$ of 19 patients (Table 1). Thus, s-MKRN1-Abs can be a candidate of diagnostic markers of esophageal SCC with low false positive rates.

There was no correlation between the presence of sMKRN1-Abs and clinicopathological variables except histological grading (Table 1). Well-differentiated type tumors were observed more frequently in the patients with s-MKRN1-Abs than in the patients without sMKRN1-Abs. This is consistent with the report of Hirotsune et al. that MKRN1 has a crucial role in differentiation [32]. 


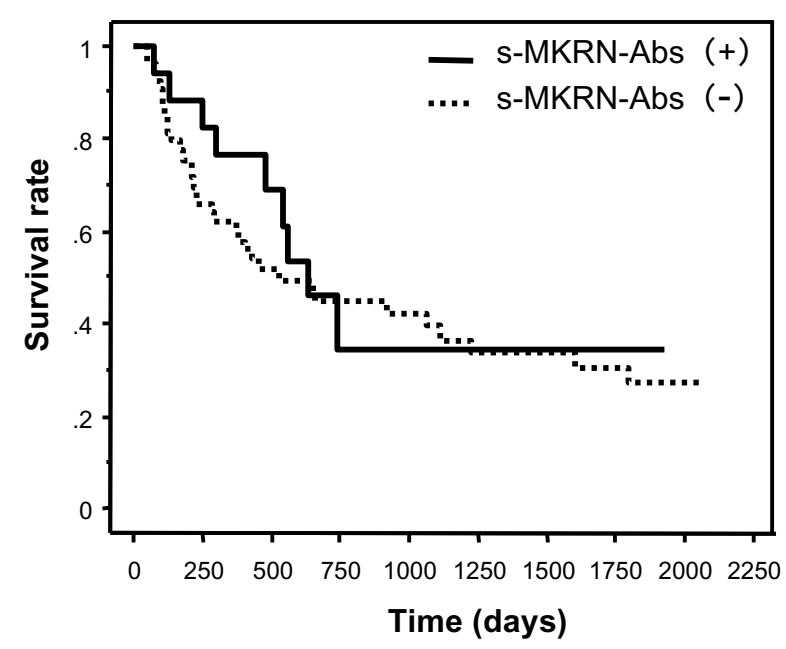

Figure 2

Kaplan-Meier overall survival curves for the patients with or without s-MKRN I-Abs. Logrank (Mantel-Cox) Pvalue $=0.5209$.

RT-PCR analysis showed that the expression of MKRN1 mRNA was frequently higher in esophageal SCC tissues than in the peripheral normal esophageal mucosa (Figure 3). Densitometric analysis revealed that the relative expression levels of MKRN1 versus $\beta$-actin mRNA in esophageal SCC were approximately 2.5 -fold higher than in the normal esophageal mucosa. This elevated expression may, in part, account for the development of serum antibodies, and give a rationale of application of sMKRN1-Abs as a tumor marker.

Stable transfection of ras-NIH3T3 cells with MKRN1 cDNA showed prominent morphological changes (Figure

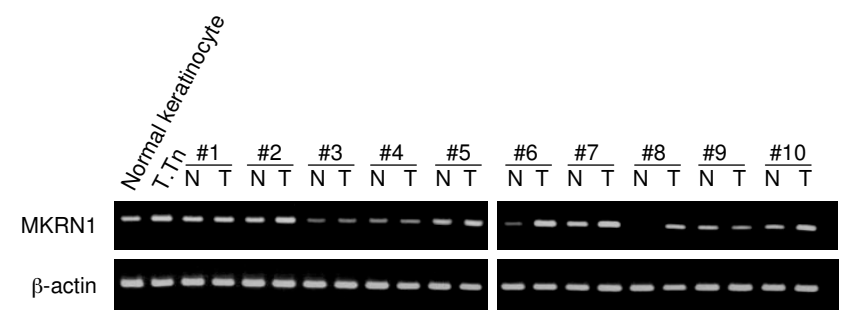

\section{Figure 3}

Elevated levels of MKRN I mRNA in esophageal SCC tissues. MKRNI (upper panel) and $\beta$-actin (lower panel) mRNA levels were examined by RT-PCR in specimens of normal $(\mathrm{N})$ and carcinoma $(\mathrm{T})$ tissues resected from patients I to I0 (\#I - \#I0). 'Normal keratinocyte' and 'T.Tn' represent the products from RNA of normal esophageal keratinocytes obtained from Cybrdi and the T.Tn esophageal SCC cell line, respectively. a
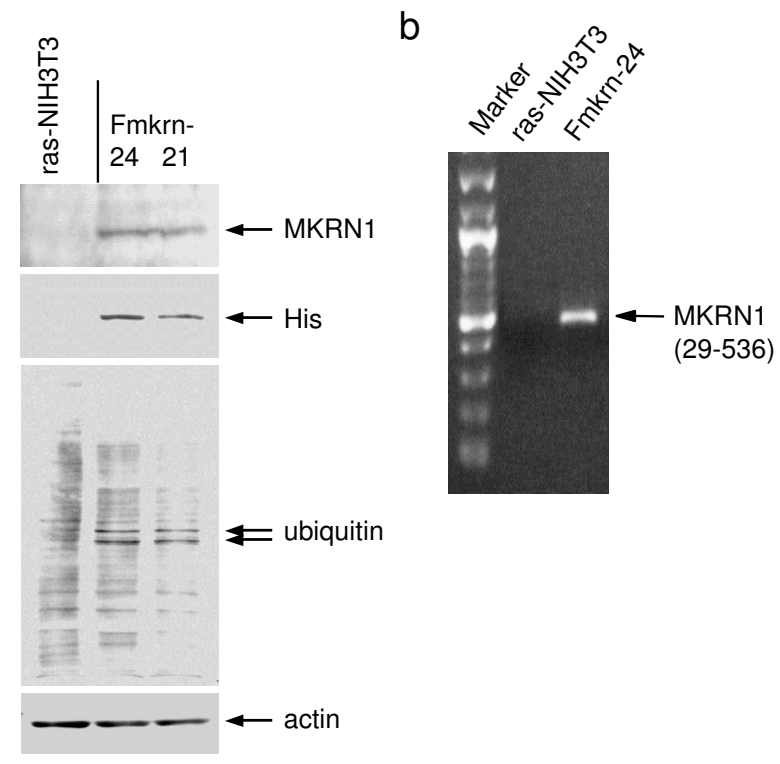

C ras-NIH3T3
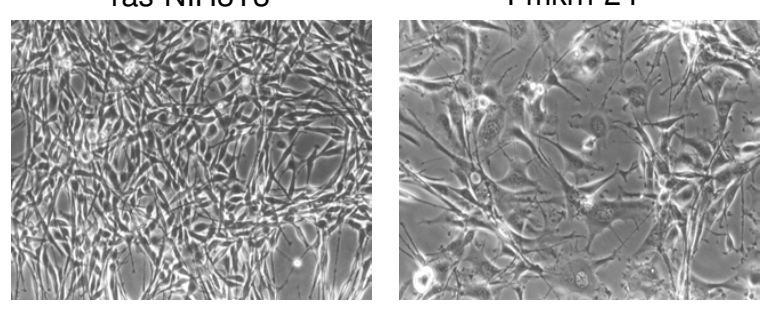

Figure 4

Isolation of stable MKRN I transfectants. (a) Protein expression levels of MKRNI, His-tagged proteins, ubiquitinated proteins and $\beta$-actin in MKRNI transfectants, Fmkrn24 and $2 I$, and the parental ras-NIH3T3 cells were examined by Western blotting using the anti-MKRNI peptide antibody, the anti-His antibody (lower panel), the anti-ubiquitin antibody or the anti- $\beta$-actin antibody. (b) Expression of MKRNI mRNA in MKRNI transfectant Fmkrn-24 and ras-NIH3T3 cells was examined by RT-PCR. MKRNI sequence between nucleotide positions 29 and 536 was amplified. The position of PCR products is indicated by an arrow. (c) Phase morphology of ras-NIH3T3 and Fmkrn-24 cells. Original magnification, $\times 100$.

4), which resembled phenotypic reversion of ras-NIH3T3 cells to NIH3T3-like cells [34]. This suggests an effect of MKRN1 on actin cytoskeleton because such changes were frequently associated with reorganization of actin stress fibers [35]. In addition, ubiquitination of $80-$ and $82-\mathrm{kDa}$ proteins was induced by transfection with two MKRN1transfected cells (Figure 4a). Mass spectrometry revealed that these ubiquitinated proteins are L-FILIP (Figure 5). FILIP interacts with filamin A, a component of stress fibers, and induces degradation of filamin A, leading to alter- 


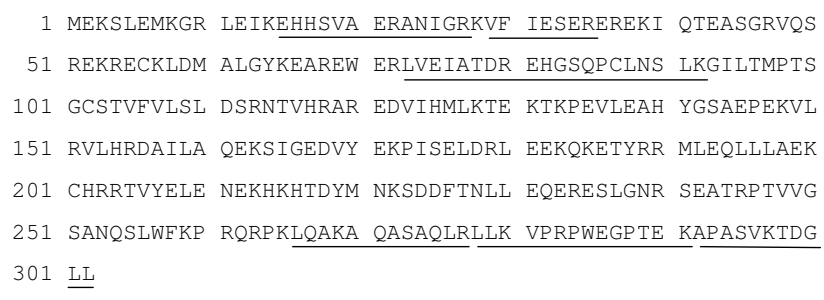

\section{Figure 5}

Identification of L-FILIP as MKRN I-induced ubiquitinated proteins. Ubiquitinated proteins of 80 and $82 \mathrm{kDa}$ in Fmkrn-24 cells were immunoprecipitated with anti-ubiquitin antibody followed by SDS-polyacrylamide gel electrophoresis. The gel pieces containing the 80 - and $82-k D a$ proteins were excised, and the tryptic peptides were analyzed by mass spectrometry. Amino acid sequences of L-FILIP are shown. The identical amino acids sequences between the analyzed peptides and L-FILIP are shown by underlines.

ation of cell shape and decrease in cell motility [36,37]. Therefore, MKRN1-induced ubiquitination of L-FILIP followed by degradation with proteasome system may explain the prominent morphological changes in MKRN1-transfected cells as well as the effects on differentiation.

The expression of MKRN1 is increased in half ( 5 out of 10 cases) but not all esophageal SCC tissues (Figure 3). Therefore, it is implausible that MKRN1 has an indispensable role in esophageal carcinogenesis. However, involvement in differentiation and the effects on the cytoskeleton via L-FILIP suggest that MKRN1 has a key role in a certain type of esophageal carcinogenesis. Suppression of MKRN1 activity might be a novel strategy for esophageal SCC therapy.

\section{Conclusion}

It is plausible that MKRN1 is involved in differentiation and carcinogenesis of a certain type of esophageal SCC. sMKRN1-Abs can be a candidate of diagnostic markers of esophageal SCC.

\section{Abbreviations}

IPTG: isopropyl $\beta$-D-thiogalactoside; ORF: open reading frame; RT-PCR: reverse transcription-PCR; SCC: squamous cell carcinoma; SEREX: serological identification of antigens by recombinant cDNA expression cloning; sMKRN1-Abs: serum anti-MKRN1 antibodies.

\section{Competing interests}

The authors declare that they have no competing interests.

\section{Authors' contributions}

HS carried out gene manipulation and the statistical analysis. TS carried out the immunoassays. MY carried out expression cloning. AK carried out gene expression analysis. MK carried out transfection experiments. FN and MT participated in coordination. TO and HM contributed in the clinicopathological analysis. TH participated in the design of the study. All authors read and approved the final manuscript.

\section{Acknowledgements}

This work was supported by 21 st Century COE (Center of Excellence) Program from the Ministry of Education, Culture, Sports, Science and Technology of Japan and Grant-in-Aid for Scientific Research (\#17591370 and \#16390372) from the Ministry of Education, Culture, Sports, Science and Technology of Japan. We thank Ms. Masae Suzuki and Akiko Kimura for their technical assistance.

\section{References}

I. Isono K, Ochiai T: Recent advances of treatment of cancer of the esophagus (review). Ann Cancer Res Therapy 1992, 1:9-16.

2. Daly JM, Karnell LH, Menck HR: National cancer data base report on esophageal carcinoma. Cancer 1996, 78:1820-1828.

3. Shimada H, Kitabayashi H, Nabeya $\mathrm{Y}$, Okazumi S, Matsubara H, Funami Y, Miyazawa Y, Shiratori T, Uno T, Itoh H, Ochiai T: Treatment response and prognosis of patients after recurrence of esophageal cancer. Surgery 2003, 133:24-31.

4. Shimada H, Nabeya $Y$, Okazumi S, Matsubara H, Miyazawa $Y$, Shiratori $T$, Hayashi $H$, Gunji $Y$, Ochiai $T$ : Prognostic significance of CYFRA $2 \mathrm{I}-\mathrm{I}$ in patients with esophageal squamous cell carcinoma. J Am Coll Surg 2003, 196:573-578.

5. Shimada H, Nabeya $Y$, Okazumi S, Matsubara H, Shiratori T, Gunji $Y$, Kobayashi S, Hayashi G, Ochiai T: Prediction of survival with squamous cell carcinoma antigen in patients with resectable esophageal squamous cell carcinoma. Surgery 2003, 133:486-494.

6. Foley E): Attempts to induce immunity against mammary adenocarcinoma in inbred mice. Cancer Res 1953, 13:578-580.

7. Prehn RT, Main JM: Immunity to methylcholanthrene-induced sarcomas. I Natl Cancer Inst 1957, I 8:769-778.

8. Sahin U, Türeci $O$, Schmitt $H$, Cochlovius $B$, Johannes $T$, Schmits $R$, Stenner F, Luo G, Schobert I, Pfreundschuh M: Human neoplasms elicit multiple specific immune responses in the autologous host. Proc Natl Acad Sci USA 1995, 92: I I8I 0 - I I8I3.

9. Chen YT, Scanlan MJ, Sahin U, Türeci O, Gure AO, Tsang S, Williamson $B$, Stockert $E$, Pfreundschuh $M$, Old LJ: A testicular antigen aberrantly expressed in human cancers detected by autologous antibody screening. Proc Natl Acad Sci USA 1997, 94:1914-1918.

10. Cancer immunome database [http://www2.licr.org/Cancerlm munomeDB/]

II. Shimada H, Takeda A, Arima M, Okazumi S, Matsubara H, Nabeya $Y$, Funami $Y$, Hayashi H, Gunji Y, Suzuki T, Kobayashi S, Ochiai T: Serum p53 antibody is a useful tumor marker in superficial esophageal squamous cell carcinoma. Cancer 2000, 89:1677-1683.

12. Shimada H, Nakajima $\mathrm{K}$, Ochiai T, Koide $\mathrm{Y}$, Okazumi S, Matsubara $\mathrm{H}$, Takeda A, Miyazawa Y, Arima M, Isono K: Detection of serum p53 antibodies in patients with esophageal squamous cell carcinoma: correlation with clinicopathologic features and tumor markers. Oncol Rep 1998, 5:87|-874.

13. Shimada H, Nabeya $Y$, Okazumi S, Matsubara H, Funami $Y$, Shiratori T, Hayashi H, Takeda A, Ochiai T: Prognostic significance of serum p53 antibody in patients with esophageal squamous cell carcinoma. Surgery 2002, I32:4 |-47.

14. Nakashima K, Shimada H, Ochiai T, Kuboshima M, Kuroiwa N, Okazumi S, Matsubara H, Nomura F, Takiguchi M, Hiwasa T: Serological identification of TROP2 by recombinant cDNA expression cloning using sera of patients with esophageal squamous cell carcinoma. Int / Cancer 2004, I I 2: 1 029- I035.

15. Shimada H, Nakashima K, Ochiai T, Nabeya Y, Takiguchi M, Nomura $F$, Hiwasa $T$ : Serological identification of tumor antigens of esophageal squamous cell carcinoma. Int J Oncol 2005, 26:77-86. 
16. Kuboshima M, Shimada H, Liu TL, Nakashima K, Nomura F, Takiguchi $M$, Hiwasa T, Ochiai T: Identification of a novel SEREX antigen, SLC2AI/GLUTI, in esophageal squamous cell carcinoma. Int I Oncol 2006, 28:463-468.

17. Kuboshima M, Shimada H, Liu T-L, Nomura F, Takiguchi M, Hiwasa T, Ochiai T: Presence of serum TRIM2I antibodies in patients with esophageal squamous cell carcinoma. Cancer Sci 2006, 97:380-386.

18. Hiwasa T, Shimada H, Ochiai T, Takiguchi M: Serological identification of antigens by recombinant cDNA expression cloning (SEREX) using antibodies from patients with esophageal squamous cell carcinoma. In Moleculomics and Thereafter Edited by: Hiwasa T. Kerala, India: Research Signpost; 2006:99-II 7.

19. Shimada H, Kuboshima M, Shiratori T, Nabeya Y, Takeuchi A, Takagi H, Nomura F, Takiguchi M, Ochiai T, Hiwasa T: Serumanti-myogegalin antibodies in patients with esophageal squamous cell carcinoma. Int J Oncol 2007, 30:97-103.

20. Shiratori T, Shimada H, Kagaya A, Kuboshima M, Nabeya Y, Machida T, Goto K, Takiguchi M, Ochiai T, Hiwasa T: Sensitization against anticancer drugs by transfection with UBE2I variant gene into ras-NIH3T3 mouse fibroblasts. Anticancer Res 2007 , 27:3227-3234.

21. Hiwasa T, Shimada H, Kuboshima M, Shiratori T, Kagaya A, Nabeya Y, Sugano S, Ochiai T, Matsubara H, Takiguchi M: Decrease in chemosensitivity against anticancer drugs by an esophageal squamous cell carcinoma SEREX antigen, AISEC. Int J Oncol 2009, 34:64l-648.

22. Takahashi K, Kanazawa H, Chan H, Hosono T, Takahara M, Sato K: A case of esophageal carcinoma metastatic to the mandible and characterization of two cell lines (T.T. and T.Tn.). Jpn J Oral Maxillofac Surg 1990, 36:307-316.

23. Shimada H, Shimizu T, Ochiai T, Liu TL, Sashiyama H, Nakamura A, Matsubara H, Gunji Y, Kobayashi S, Tagawa M, Sakiyama S, Hiwasa T: Preclinical study of adenoviral p53 gene therapy for esophageal cancer. Surg Today 200 I, 3 I:597-604.

24. Chomczynski P, Sacchi N: Single-step method of RNA isolation by acid guanidinium thiocyanate-phenol-chloroform extraction. Anal Biochem 1987, I62:156-159.

25. Sobin $\mathrm{LH}$, Wittekind $\mathrm{CH}$, (Eds): UICC TNM Classification of malignant tumors. 6th edition. New York: John Wiley \& Sons; 2000.

26. Laemmli UK: Cleavage of structural proteins during the assembly of the head of bacteriophage. Nature 1970, 227:680-685.

27. Sekiya T, Fushimi M, Mori H, Hirohashi S, Nishimura S, Sugimura T: Molecular cloning and the total nucleotide sequence of the human c-Ha-ras-I gene activated in melanoma from a Japanese patient. Proc Natl Acad Sci U S A. 1998, 8 I ( I 5):477| -4775.

28. Hiwasa T, Shimada H, Sakaida T, Kitagawa M, Kuroiwa N, Ochiai T, Takiguchi M: Drug-sensitivity pattern analysis of study of functional relationship between gene products. FEBS Lett 2003, 552: $177-183$.

29. Liu TL, Shimada H, Ochiai T, Shiratori T, Lin S-E, Kitagawa M, Harigaya K, Maki M, Oka M, Abe T, Takiguchi M, Hiwasa T: Enhancement of chemosensitivity toward peplomycin by calpastatinstabilized NF- $\kappa$ B p65 in esophageal carcinoma cells: possible involvement of Fas/Fas-L synergism. Apoptosis 2006, I I:1025-1037.

30. Hiwasa T, Kominami E: Physical association of Ras and cathepsins $B$ and $L$ in the conditioned medium of v-Ha-ras-transformed NIH3T3 cells. Biochem Biophys Res Commun 1995, 21 6:828-834.

31. Gray TA, Hernandez L, Carey AH, Schaldach MA, Smithwick MJ, Rus K, Graves JAM, Stewart CL, Nicholls RD: The ancient source of a distinct gene family encoding proteins featuring RING and C(3)H zinc-finger motifs with abundant expression in developing brain and nervous system. Genomics 2000, 66:76-86.

32. Hirotsune S, Yoshida N, Chen A, Garrett L, Sugiyama F, Takahashi S, Yagami K, Wynshaw-Boris A, Yoshiki A: An expressed pseudogene regulates the messenger-RNA stability of its homologous coding gene. Nature 2003, 423:91-96.

33. Kim JH, Park S-M, Kang MR, Oh S-Y, Lee TH, Muller MT, Chung IK: Ubiquitin ligase MKRNI modulates telomere length homeostasis through a proteolysis of hTERT. Genes Dev 2005, | 9:776-78|.
34. Hiwasa T, Nakata M, Nakata M, Ohno S, Maki M, Suzuki K, Takiguchi M: Regulation of transformed state by calpastatin via PKC $\varepsilon$ in NIH3T3 mouse fibroblasts. Biochem Biophys Res Commun 2002, 290:510-517.

35. Sakiyama S, Hiwasa T: Disorganization of microfilaments caused by tumor promoters in mouse fibroblasts. Gann. I98I, 75(I):4-7.

36. Nagano T, Yoneda T, Hatanaka Y, Kubota C, Murakami F, Sato M: Filamin A-interacting protein (FILIP) regulates cortical cell migration out of the ventiricular zone. Nat Cell Biol 2002, 4:495-501.

37. Sato $M$, Nagano $T$ : Involvement of filamin $\mathbf{A}$ and filamin $\mathbf{A}$ interacting protein (FILIP) in controlling the start and cell shape of radially migrating cortical neurons. Anat Sci Int 2005, 80:19-29.

\section{Pre-publication history}

The pre-publication history for this paper can be accessed here:

http://www.biomedcentral.com/1471-2407/9/232/pre pub
Publish with Bio Med Central and every scientist can read your work free of charge

"BioMed Central will be the most significant development for disseminating the results of biomedical research in our lifetime. "

Sir Paul Nurse, Cancer Research UK

Your research papers will be:

- available free of charge to the entire biomedical community

- peer reviewed and published immediately upon acceptance

- cited in PubMed and archived on PubMed Central

- yours - you keep the copyright
BioMedcentral 